\title{
Applicability of Reddish Orange Light Emitting Samarium (III) Complexes For Biomedical and Multifunctional Optoelectronic Devices
}

\section{Pooja Hooda}

Maharshi Dayanand University Rohtak

\section{B. Taxak}

Maharshi Dayanand University Rohtak

R. K. Malik

Maharshi Dayanand University Rohtak

Savita Khatri

Maharshi Dayanand University Rohtak

Poonam Kumari

Maharshi Dayanand University Rohtak

\section{S. P. Khatkar}

Maharshi Dayanand University Rohtak

Rajesh Kumar ( $\square$ lather_rajesh@yahoo.com )

Maharshi Dayanand University Rohtak https://orcid.org/0000-0002-1070-9967

\section{Research Article}

Keywords: Photostimulated, CCT, refractive index, reddish-orange, samarium (III) complex

Posted Date: November 30th, 2021

DOI: https://doi.org/10.21203/rs.3.rs-1087950/v1

License: (9) (1) This work is licensed under a Creative Commons Attribution 4.0 International License. Read Full License

Version of Record: A version of this preprint was published at Journal of Fluorescence on January 12th, 2022. See the published version at https://doi.org/10.1007/s10895-021-02887-x. 


\section{Abstract}

Six crimson samarium (III) complexes based on $\beta$-ketone carboxylic acid and ancillary ligands were synthesized by adopting grinding technique. All synthesized complexes were investigated via employing elemental analysis, infrared, UV-Vis, NMR, TG/DTG and photoluminescence studies. Optical properties of these photostimulated samarium (III) complexes exhibit reddish-orange luminescence due to ${ }^{4} \mathrm{G}_{5 / 2} \rightarrow{ }^{6} \mathrm{H}_{7 / 2}$ transition at $606 \mathrm{~nm}$ of samarium (III) ions. Further, energy band gap, color purity, CIE color coordinates, CCT and quantum yield of all complexes were determined accurately. Replacement of water molecules by ancillary ligands enriched the complexes (S2-S6) with decay time, quantum yield, luminescence, energy band gap and biological properties than parent complex (S1). Interestingly, these efficient properties of complexes may find their applications in optoelectronic and lighting systems. In addition to these the antioxidant and antimicrobial assays were also investigated to explore the application in biological assays.

\section{Introduction}

From last few decades, lanthanide materials gathered the special attention due to their versatile applications in various fields like lasers[1], OLEDs[2], display devices[3], LED bulbs [4] and biological systems[5]. Hence, synthesis of lanthanides complexes with prominent high quantum yield, large stock shifts and long luminescence decay time has become a hot research topic at present time. Lanthanide complexes possess luminescence due to $4 \mathrm{f}-4 \mathrm{f}$ transitions, which are Laporte forbidden according to spin parity rule [6]. Hence, direct excitation in lanthanides is not beneficial as it results in low molar absorptivity and weak luminescence[7, 8]. In order to overcome this catastrophe, a light harvesting chromophore was incorporated in coordination sphere which absorb energy from external source and transfer to lanthanides via antenna effect[9]. Generally, $\beta$-hydroxy ketone, $\beta$-keteocarboxylic acid and aromatic carboxylic acid are vigilantly studied due to their significant ability to transfer the absorbed energy from external source to lanthanides[10,11]. However, $\beta$-keteocarboxylic acid is an excellent chromophore to generated excellent reddish orange emission for display devices and other applications. Further, specially Eu (III), Tb (III) and Sm (III) having unique optical properties such as narrow emission bands, long decay time, large stock shifts and high luminescence due to electronic transitions in emission spectra[12]. Out of these, samarium (III) complexes grab significant attention due to their ability to emit reddish orange $(606 \mathrm{~nm})$ emission utilized in high quality display devices.

Currently, six scarlet samarium (III) complexes have been prepared by utilizing 1-cyclopropyl-6-fluro-4-oxo-7-piperazin1-ylquinoline-3-carboxylic acid (L), bathophenanthroline (batho), 1,10-phenanthroline (phen), neocuproine (neo), 2,2'bipyridyl (bipy) and 5,6-dimethyl-1,10-phenanthroline (dmph) ligands via grinding technique. All synthesized complexes were investigated via utilizing UV-Vis, ${ }^{13} \mathrm{C}-\mathrm{NMR},{ }^{1} \mathrm{H}-\mathrm{NMR}$ and IR spectroscopy. The information regarding elemental composition and thermal stability can be achieved by using elemental and thermogravimetric analysis. The

photoluminescent spectra and decay time are executed effectively for reporting the photoluminescent aspects of samarium (III) complexes. The emitting color of complexes is confirmed by colorimetric parameters (color purity and $\mathrm{CIE}$ ) of complexes. The sensitization of samarium ion by ligand can be well illustrated by investigation of energy transfer process in detail. To assess the antioxidant and antimicrobial activities, complexes are screened for DPPH and tube dilution techniques respectively.

\section{Experimental}

\subsection{Reagents and instruments}


All solvents and chemicals were of analytical reagent grade with a stated purity $99 \%$ acquired from commercial source named Sigma Aldrich and used as such without further purification. The photoluminescence spectra were executed on spectrophotometer (Hitachi F-7000) equipped with xenon lamp. The elemental analyses enquired on Perkin Elmer $2400 \mathrm{CHN}$ elemental analyser. Thermal stability was checked up to $800^{\circ} \mathrm{C}$ temperature on SDT Q 600 analyzer with $20^{\circ} \mathrm{C} / \mathrm{min}$ in nitrogen atmosphere. ${ }^{1} \mathrm{H}$ and ${ }^{13} \mathrm{C}$ NMR spectra were performed on Bruker Avance II spectrophotometer in DMSO at $400 \mathrm{MHz}$ frequency. IR spectra were obtained by perkin Elmer 400 spectrophotometer using $\mathrm{KBr}$ pellet in $4000 \mathrm{~cm}^{-1}$ to $400 \mathrm{~cm}^{-1}$. The decay time value was determined via the FL solutions software F7000 by monitoring ${ }^{4} \mathrm{G}_{5 / 2} \rightarrow{ }^{6} \mathrm{H}_{7 / 2}$ emission line of $\mathrm{Sm}^{3+}$ in solid state. The UV-Vis absorption spectra were executed on Shimadzu-2450 spectrophotometer. DPPH and tube dilution technique were used to investigate the antioxidant and antimicrobial activities respectively.

\subsection{Preparation of complexes}

To synthesize the complex S1, ligand $(0.498 \mathrm{~g})$ and samarium nitrate hexahydrate $(0.222 \mathrm{~g})$ were placed in mortar and grinded properly. In order to mix all contents appropriately few drops of water added and $\mathrm{pH}$ of solution was adjusted at 7 with the help of $\mathrm{NaOH}(0.01 \mathrm{M})$ solution. Resulting paste was purified by dissolving in $10 \mathrm{~mL}$ water and centrifuged for 2 minutes, moreover, same procedure was repeated for 2-3 times and dried the resultant sample in oven at $50{ }^{\circ} \mathrm{C}$. Same steps were repeated by adding ancillary ligands such as bipy $(0.078 \mathrm{~g}) \mathrm{S} 2$, neo (0.104 g) S 3 , dmph $(0.104 \mathrm{~g}) \mathrm{S} 4$, batho $(0.161 \mathrm{~g}) \mathrm{S} 5$ and phen $(0.09 \mathrm{~g}) \mathrm{S} 6$ supplemented to the mortar having $\mathrm{L}$ and $\mathrm{Sm}\left(\mathrm{NO}_{3}\right) \cdot 6 \mathrm{H}_{2} \mathrm{O}$. To portray the energy transfer dynamics triplet state of ligands were considered, for which same procedure repeated to prepare corresponding gadolinium complexes. The synthetic route and structure of all samarium complexes via utilizing grinding technique was displayed in scheme 1[13].

\subsection{Evaluation of biological Activities}

\subsubsection{Antioxidant activities}

DPPH (2,2-diphenyl-1-picrylhydrazyl) protocol was adopted to compute the antioxidant activities of all referred complexes. The stable free radical DPPH lost its violet color and change into pale yellow due to association with antioxidants moiety, which results a significant drop in absorption at $517 \mathrm{~nm}$ on spectrophotometer. In order to prepare numerous concentrations such as $25,50,75$ and $100 \mu \mathrm{g} / \mathrm{mL}$, dimethylsulfoxide (DMSO) was used as a solvent. Further, $1 \mathrm{~mL}$ DPPH solution was added to the $1 \mathrm{~mL}$ solution of each test samples in their corresponding flasks. The absorbance was recorded after 30 minute incubation in dark at $25^{\circ} \mathrm{C}$ by taking ascorbic acid as a standard. All tests were performed in triplicate to get concordant values and the scavenging activity of DPPH is expressed in $\mathrm{IC}_{50}$ (50\% of maximum scavenging activity) values. The $\mathrm{IC}_{50}$ value was determined by graph plotting between scavenging activity (SCA) and numerous concentrations of test samples. By using equation 1 the DPPH scavenging activity of all test samples was determined[14]:

DPPH scavenge activity $(\%)=\frac{\mathrm{A}_{\mathrm{C}^{-}} \mathrm{A}_{\mathrm{t}}}{\mathrm{A}_{\mathrm{C}}}$

Where $A_{t}$ and $A_{c}$ refers to the absorbance test samples and control reaction respectively.

\subsubsection{Antimicrobial activities}

Antimicrobial assays were executed for all title complexes by employing tube dilution protocol[15]. Antibacterial activities of these samples were carried out against the following in vitro gram negative bacteria: Pseudomonas aeruginosa (MTCC1688), Escherichia coli (MTCC 443) and in vitro gram positive bacteria: Streptococcus pyogenes 
(MTCC442), Staphylococcus aureus (MTCC 96). Antifungal activities of these complexes were screened against the fungal strain takes Candida albicans (MTCC 227), Aspergillus clavatus (MTCC 1323) and Aspergillus niger (MTCC 282). The reference drugs norfloxacin and greseofulvin were used for antibacterial and antifungal activities respectively.

All samples (reference + ligand + complexes) were dissolved in DMSO to give concentration of $200 \mu \mathrm{g} / \mathrm{mL}$. The incubation period for antibacterial activities is $24 \mathrm{~h}$ at $37^{\circ} \mathrm{C}$ and for antifungal activities is 7 days at $24^{\circ} \mathrm{C}$ for Aspergillus avatus and Candida albicans but $48 \mathrm{~h}$ at $37^{\circ} \mathrm{C}$ for Aspergillus niger[16]. The zone of inhibition of antimicrobial activities has been recorded in MIC values.

\section{Results And Discussion}

\subsection{Elemental analysis}

Table 1 displays the elemental analytic data from $\mathrm{CHN}$ elemental analyser, which had been estimated to be in complete harmony with the calculated values and recommend $\left[\mathrm{Sm}(\mathrm{L})_{3} \cdot\left(\mathrm{H}_{2} \mathrm{O}\right)_{2}\right] \cdot 6 \mathrm{H}_{2} \mathrm{O}(\mathrm{S} 1),\left[\mathrm{Sm}(\mathrm{L})_{3} \cdot\right.$ bipy].6 $\mathrm{H}_{2 \mathrm{~s}} \mathrm{O}(\mathrm{S} 2)$,

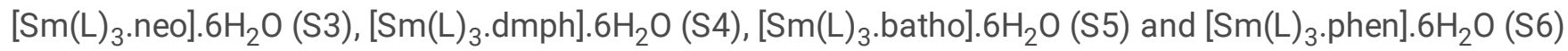
respectively as the proposed formula.

Table 1

The elemental analytical data for all S1-S6 Samarium (III) complexes.

\begin{tabular}{|lllll|}
\hline Complexes & $\mathbf{C}(\%)$ found (cal.) & $\mathbf{H}(\%)$ found (cal.) & $\mathbf{N}(\%)$ found (cal.) & Sm(\%) found(cal.) \\
\hline S 1 & $42.74(42.76)$ & $5.98(6.01)$ & $8.78(8.80)$ & $10.46(10.48)$ \\
\hline S 2 & $47.42(47.46)$ & $5.72(5.77)$ & $9.58(9.66)$ & $9.40(9.41)$ \\
\hline S 3 & $47.64(46.65)$ & $5.84(5.86)$ & $9.79(9.81)$ & $9.54(9.56)$ \\
\hline S 4 & $51.56(1.57)$ & $5.70(5.73)$ & $8.79(8.82)$ & $8.58(8.59)$ \\
\hline S 5 & $48.09(48.11)$ & $5.90(5.92)$ & $9.47(9.50)$ & $9.23(9.25)$ \\
\hline S 6 & $48.03(48.11)$ & $5.89(5.92)$ & $9.48(9.50)$ & $9.22(9.25)$ \\
\hline
\end{tabular}

\subsection{Spectral analysis}

Figure 1 represents the infrared spectrum of complex $S 1$ and free ligand $(L)$, to evaluate the chelation site in bonding. The IR spectra of S 2- S 6 complexes show that all complexes have almost identical IR spectra as displayed in Figure S1 in supplementary file. The position and intensity of some guide peaks are changed from ligand to complexes, which help to find the binding site in complexes. The broad band scrutinized at $3410 \mathrm{~cm}^{-1}$ depicts the presence of aqua molecule in all synthesized (S1-S6) complexes[17]. In ligand spectra the band noted at $1711 \mathrm{~cm}^{-1}$ and 1625 $\mathrm{cm}^{-1}$ reflects the existence of carboxylic and ketonic group respectively. It is important to note that the band due to carboxylic acid $\left(1711 \mathrm{~cm}^{-1}\right)$ completely disappeared in synthesized complexes, peak in all S1-S6 complexes signalize the chelation through carboxylato group. Additionally, bands due to ketonic group $\left(1625 \mathrm{~cm}^{-1}\right)$ shift in all S1-S6 complexes (Table 2) revealing that the second chelation site is through ketonic oxygen. The asymmetric and symmetric vibrations of carboxylato group appears at 1585-1592 cm-1 and 1370-1375 $\mathrm{cm}^{-1}$ respectively which are absent in ligand spectra[18]. Further, carboxylate group is a bidentate ligand, hence, can bind either as unidentate or as bidentate by producing change in relative vibrational positions of asymmetric and symmetric stretching. 
Complexes exhibits $\Delta v>200 \mathrm{~cm}^{-1}\left[\Delta \mathrm{v}=\Delta \mathrm{v}_{\mathrm{as}}\left(\mathrm{COO}^{-}\right)-\Delta \mathrm{v}_{\mathrm{s}}\left(\mathrm{COO}^{-}\right)\right]$, this demonstrates the unidentate linkage of carboxylic group[19]. The observed $\Delta v$ values for all synthesized S1-S6 complexes are found to be $210-220 \mathrm{~cm}^{-1}$ as enlisted in Table2, suggesting the unidentate attraction of carboxylato group. Further, the new band appeared at 459$464 \mathrm{~cm}^{-1}, 539-548 \mathrm{~cm}^{-1}$ and $1481-1486 \mathrm{~cm}^{-1}$ in S2-S6 complexes assigned for stretching vibrations of $\mathrm{v}_{\mathrm{Sm}-0}, \mathrm{v}_{\mathrm{Sm}-\mathrm{N}}$ and $\mathrm{v}_{\mathrm{C}-\mathrm{N}}$ respectively in all synthesized complexes as elucidated in Table 2.

Table 2

The characteristic IR bands $\left(\mathrm{cm}^{-1}\right)$ for ligand and its samarium (III) complexes.

\begin{tabular}{|c|c|c|c|c|c|c|c|c|c|}
\hline Compounds & $\mathbb{\mathrm { O }}_{\mathrm{OH}}$ & $\mathbb{\mathrm { D }}_{\mathrm{COOH}}$ & $\mathbb{\Delta}_{\mathrm{sm}-0}$ & $\mathbb{}_{\mathrm{Sm}-\mathrm{N}}$ & $\mathbb{\nabla}_{\mathrm{C}=\mathrm{N}}$ & $\mathbb{D}_{C=0}$ & $\begin{array}{l}\mathbb{X}_{\mathrm{as}} \\
\text { (co0-) }\end{array}$ & $\mathbb{D}_{s(\mathrm{COO}-)}$ & $\begin{array}{l}\Delta \mathrm{Q}_{\mathrm{COO}}{ }^{-} \\
\left(\mathrm{\nabla}_{\mathrm{as}-} \mathrm{\nabla}_{\mathrm{s}}\right)\end{array}$ \\
\hline L & - & $3530(S)$ & - & - & - & 1625(S) & - & - & - \\
\hline S 1 & $3410(\mathrm{~B})$ & - & $464(W)$ & - & - & 1624(S) & $1590(S)$ & $1370(S)$ & 220 \\
\hline S 2 & $3410(B)$ & - & $463(W)$ & $548(W)$ & $1483(W)$ & $1620(S)$ & $1588(S)$ & $1372(S)$ & 216 \\
\hline S 3 & $3410(B)$ & - & $462(W)$ & $547(W)$ & $1481(W)$ & 1622(S) & $1589(S)$ & 1374(S) & 215 \\
\hline S 4 & $3410(B)$ & - & $459(W)$ & $539(W)$ & 1482(W) & $1623(\mathrm{~S})$ & $1585(S)$ & $1375(S)$ & 210 \\
\hline S 5 & $3410(B)$ & - & $460(W)$ & $545(W)$ & $1486(W)$ & 1622(S) & $1590(\mathrm{~S})$ & $1372(S)$ & 218 \\
\hline S 6 & $3410(\mathrm{~B})$ & - & $461(W)$ & $546(W)$ & 1484(W) & $1623(\mathrm{~S})$ & 1592(S) & $1373(S)$ & 219 \\
\hline
\end{tabular}

Figure 2 represents the ${ }^{1} \mathrm{H}-\mathrm{NMR}$ spectrum of free ligand and synthesized complex (S1) carried out in DMSO as a solvent. It is evident from the figure that some significant changes take place when the spectrum of complex is compared with the ligand. The anisotropic property of samarium ions is responsible for upfield and downfield shifts in complexes [20]. The peak observed at 15 ppm manifest the presence of carboxylic group in ligand, which completely disappeared in synthesized complexes, confirming the chelation of ligand through deprotonated carboxylic acid[21]. In the ligand spectra the peaks observed at 7.56 - $9.39 \mathrm{ppm}$ (aromatic $\left.-\mathrm{CH}_{2}\right), 3.26-3.98 \mathrm{ppm}$ (aliphatic $-\mathrm{CH}_{2}$ ) and 1.19-1.33 ppm (- $\left.\mathrm{CH}_{3}\right)$ are shifted to $7.54-8.66$ ppm (upfield), 2.39-2.90 ppm (upfield) and 1.18$1.31 \mathrm{ppm}$ (upfield) in complexes respectively. The paramagnetism nature of samarium (III) ions causes upfield shifting of all protons in complexes[22].

Figure S2 in supplementary file portrays the ${ }^{13} \mathrm{C}-\mathrm{NMR}$ spectrum of $\mathrm{L}$ and $\mathrm{S} 1$ complex, the carbon values noticed at 176.33 (C=0), 165.81(COOH), 139-153 (aromatic C=C), 106-118 (aromatic C-C) and 35.93-46.26 (-C- C- C-) shifted upfield in corresponding samarium (III) complexes due to paramagnetism of $\mathrm{Sm}^{3+}$ ion. It is evident from the figure that the peak of carboxylic group in ligand was completely disappeared in complex and the peak of ketonic group in ligand shifts by $7.74-7.86$ in all synthesized complexes, which depicts that chelation of $L$ in complexes through ketonic $(\mathrm{C}=0)$ and carboxylic group $\left(\mathrm{COO}^{-}\right)$respectively[23].

Figure 3 depicts the UV-Vis absorption spectra of all S1-S6 synthesized complexes and L $\left(1 \times 10^{-5} \mathrm{~mol} / \mathrm{L}\right)$ by taking DMSO as a solvent. Ligand acts as key absorption for all S1-S6 complexes because absorption displayed by these complexes is weak in $200-500 \mathrm{~cm}^{-1}$ region. It is evident from the figure that absorption maxima observed at $280 \mathrm{~nm}$ 
wavelength is assigned to $\pi-\pi^{\star}$ electronic transitions[24]. Further, the encapsulation of ancillary ligand in S2-S6 complexes upsurge the absorbance as well as saturates the coordination framework.

All results observed from spectroscopic measurements are in good agreement with each other and certifies that the chelation of ligand with samarium (III) ions through carboxylato $\left(\mathrm{COO}^{-}\right)$and ketone groups in the coordination.

\subsection{Thermal analysis}

Figure 4 reveal the thermal decomposition pattern for $\$ 1$ complex, since thermal decomposition pattern exhibited by all synthesized complexes are in similar nature, so, S1 was taken as a representative. The complex S1 exhibits $18 \%$ mass loss attributed to decomposition of 15 water molecules present outside of coordination sphere up to $88^{\circ} \mathrm{C}$. The next loss in mass is $71 \%$ accredited to collapsing of complex and removal of two water molecules and three ligand molecules up to $242^{\circ} \mathrm{C}$ to $557^{\circ} \mathrm{C}$ present in coordination sphere (i.e. complex start decomposing) [25]. At last, the oxide of samarium (III) ion remains as residue, which was further confirmed through analysis of DTG curves.

Theoretical and computed values are in good agreement with total loss of mass in complex. The complexes posses' optimum stability, hence, can be employed as luminescent materials in optoelectronic devices.

\subsection{Optical band gap \& refractive index}

Figure 5 (a) and (b) describe the plot between photon energy and absorption coefficient of all samples (L, S1-S6) and the inset denotes the diffused reflectance (DR) spectra of $L$ and corresponding complexes in their respective figures. Kubelka and Munk states that the optical band gap $\left(E_{g}\right)$ for solid samples can be calculated by transformation of $\mathrm{DR}[26]$. The equation 2 denotes the relationship between Kubelka and Munk $\left(F\left(R_{\infty}\right)\right)$ and energy band gap as given below:

$\left[F\left(R_{\infty}\right) h v\right]^{n}=C\left(h u-E_{g}\right)(2)$

Where, $E_{g}$ represent energy band gap, hu shows energy of incident photon and values of $n$ are variable having values $3,2,1.5$ and 0.5 assigned for indirect forbidden transitions, direct allowed transitions, direct forbidden transitions and indirect allowed transitions respectively. Herein, the value of $n$ is equals to 2 for direct allowed transition and the equation is written as follows:

$\left[F\left(R_{\infty}\right) h v\right]^{2}=C\left(h u-E_{g}\right)$

$F\left(R_{\infty}\right)$ denotes the Kubelka-Munk function and can be derived as follows:

$\mathrm{F}\left(\mathrm{R}_{\infty}\right)=\frac{(1-\mathrm{R} \infty)^{2}}{2 \mathrm{R} \infty}=\frac{K}{S}(4)$

Where, $S$ denotes scattering coefficient, $K$ represents absorption coefficient and $R_{\infty}$ refers to ratio of $R_{\text {normal }}$ to $R$ standard. The optical band gap values for $L$ and all synthesized samarium (III) complexes are determined by extrapolation of a tangent up to x-axis in Tauc plot. The observed values for all S1-S6 complexes and L are catalogued in Table 3. As the table illustrate that the value of energy band gap is less for complexes in comparison to the ligands, resulting a number of extra electronic states between samarium (III) ions, hence reinforcement of energy transfer increases, so photoluminescence also increase[27]. Therefore, the property of large energy band gap values makes them a promising candidate for semiconductor power appliance. 
Table 3

The energy band gap and refractive indices for ligand and all S1-S6 complexes.

\begin{tabular}{|lll|}
\hline Compounds & Energy band gap $\left(\mathrm{E}_{\mathrm{g}}\right)$ & Refractive Index \\
\hline $\mathrm{L}$ & 3.14 & 2.012 \\
\hline S 1 & 3.04 & 2.035 \\
\hline S 2 & 2.81 & 2.081 \\
\hline S 3 & 2.93 & 2.056 \\
\hline S 4 & 2.97 & 2.048 \\
\hline S 5 & 2.91 & 2.061 \\
\hline S 6 & 2.94 & 2.054 \\
\hline
\end{tabular}

Further, in order to find out the refractive index (n) of all S1-S6 complexes precisely, the energy band values are employed by the following relation [28]:

$$
\frac{\left(n^{2}-1\right)}{\left(n^{2}+1\right)}=1-\sqrt{\frac{E_{g}}{20}}(5)
$$

Where, $n$ represent the refractive index and $E_{g}$ signifies energy band gap values, the estimated value for all synthesized are epitomized in Table 3. The refractive index values enable these complexes as a promising candidate in optoelectronic devices.

\subsection{Photoluminescence features}

Figure 6(a) indicates the excitation spectra of all S1-S6 complexes by monitoring the ${ }^{4} \mathrm{G}_{5 / 2} \rightarrow{ }^{6} \mathrm{H}_{7 / 2}$ electronic transition at $606 \mathrm{~nm}$. Formation of complex extend the $\pi$ - conjugation, hence, the intramolecular energy transfer from $L$ to $\mathrm{Sm}^{3+}$ increases by antenna effect, this results in broadening of excitation spectra. The peak found at $360 \mathrm{~nm}$, $374 \mathrm{~nm}, 404 \mathrm{~nm}, 453 \mathrm{~nm}, 472 \mathrm{~nm}$ and $495 \mathrm{~nm}$ attributed to the electronic transitions arising from ground state ${ }^{6} \mathrm{H}_{5 / 2}$ to excited state ${ }^{4} \mathrm{~F}_{9 / 2},{ }^{4} \mathrm{D}_{5 / 2},{ }^{6} \mathrm{P}_{7 / 2},{ }^{4} \mathrm{~F}_{5 / 2}+{ }^{4} \mathrm{I}_{13 / 2},{ }^{4} \mathrm{G}_{7 / 2},{ }^{4} \mathrm{I}_{7 / 2}+{ }^{4} \mathrm{M}_{15 / 2}$ in samarium (III) ions respectively[29, 30] Figure 6(b) represents the three dimensional emission spectra of all S1-S6 complexes monitored at excitation wavelength $(356 \mathrm{~nm})$ in solid state. The luminescence spectra displays mainly three peaks at $566 \mathrm{~nm}, 606 \mathrm{~nm}$ and $651 \mathrm{~nm}$ which belongs to ${ }^{4} \mathrm{G}_{5 / 2} \rightarrow{ }^{6} \mathrm{H}_{\mathrm{j}}$ (where $\mathrm{j}=5 / 2,7 / 2,9 / 2$ ) electronic transition of samarium (III) ions in all synthesized complexes respectively. Out of these, first transition, ${ }^{4} \mathrm{G}_{5 / 2} \rightarrow{ }^{6} \mathrm{H}_{5 / 2}$, is magnetic dipole transition, which follows the selection rule of $\Delta \mathrm{J}=0$, where $\mathrm{J}$ is total angular momentum, hence intensity of this peak does not depend on coordination environment around $\mathrm{Sm}^{3+} .{ }^{4} \mathrm{G}_{5 / 2} \rightarrow{ }^{6} \mathrm{H}_{7 / 2}$ is mixed transition with (partly magnetic and partly electric dipole) but has dominating electric dipole character whereas ${ }^{4} \mathrm{G}_{5 / 2} \rightarrow{ }^{6} \mathrm{H}_{9 / 2}$ is purely electric dipole transitions. The most intense peak of spectra at $606 \mathrm{~nm}$ due to hypersensitive ${ }^{4} \mathrm{G}_{5 / 2} \rightarrow{ }^{6} \mathrm{H}_{7 / 2}$ transition is responsible for vermillion emission of complexes and makes them suitable for orange light emitting devices. This transition complies with the selection rule of $\Delta \mathrm{J}= \pm 1$, The electric dipole transition at $651 \mathrm{~nm}$ represent immensely asymmetrical surroundings around $\mathrm{Sm} 3+$ ion[31, 32]. The upsurge the photoluminescence from S1 complex to S2-S6 complexes is explained by 
introduction of ancillary ligands in place of water which results increase in radiative rate by diminished the vibrational quenching caused by water molecules.

\subsection{Luminescence decay curves and quantum yield}

The average environment surrounding samarium (III) ion is investigated by observing decay time curves under 356 $\mathrm{nm}$ excitation and $606 \mathrm{~nm}$ emission wavelengths respectively as depicted in Figure 6(c). The luminescence decay time curves are well fitted by monoexponential function and it is derived from the equation given [33]:

$\mathrm{I}=\mathrm{I}_{0} \exp (-\mathrm{t} / \tau)(6)$

Herein, $\tau$ represents the decay time for radiative transitions while $I_{0}$ and I represent the integrated intensity of peaks at time 0 and $t$, respectively. Luminescence decay time curves are best fitted in mono-exponential function, which specifies the homogenous environment around samarium (III) ion in complexes. Further, the total decay time depends upon both radiative and nonradiative as given by the following relation:

$A_{\text {total }}=1 / \tau=\left(A_{\text {rad }}+A_{\text {nrad }}\right)(7)$

The observed values of decay time for S 1 (0.72), S 2(1.40), S 3(1.78), S4 (2.02), S 5 (2.41) and S 6 (2.15) are embodied in Table 4. The observed order for decay time in complexes is found to be $\mathrm{S} 1<\mathrm{S} 2<\mathrm{S} 3<\mathrm{S} 4<\mathrm{S} 6<\mathrm{S} 5$, the higher value of decay time in S2-S6 complexes than that of S1 was credited to extended conjugation by introduction of ancillary ligands. The decay time of complexes purses single exponential behaviour which is responsible for homogenous coordination environment and single luminescent centre around central metal ion.

Table 4

Estimated quantum yield, decay time values, CIE color coordinates, color purity and CCT of all samarium (III) complexes.

\begin{tabular}{|llllll|}
\hline Complexes & Quantum yield & $\tau(\mathrm{ms})$ & CIE coordinates $(\mathbf{x}, \mathbf{y})$ & \% Color purity & CCT(K) \\
\hline S 1 & 22.22 & 0.72 & $0.5542,0.4447$ & 98.01 & 2002.15 \\
\hline S 2 & 43.20 & 1.40 & $0.5560,0.4430$ & 98.53 & 1980.13 \\
\hline S 3 & 54.93 & 1.78 & $0.5702,0.4288$ & 98.28 & 1836.01 \\
\hline S 4 & 62.34 & 2.02 & $0.5521,0.4468$ & 98.89 & 2027.39 \\
\hline S 5 & 74.38 & 2.41 & $0.5558,0.4432$ & 98.44 & 1984.02 \\
\hline S 6 & 66.35 & 2.15 & $0.5573,0.4417$ & 99.04 & 1966.83 \\
\hline
\end{tabular}

Quantum yield is an important parameter, utilized to observe the luminescence of samarium (III) ion in complexes[34]. It can be described as the ratio of numerical quantity of photons emitted to photons absorbed. However it can be calculated using following equation:

$\nabla(\%)=\frac{\tau}{\tau_{\text {rad }}} \times 100(8)$

Where, $\nabla$ represent quantum yield, $\tau$ and $\tau_{\text {rad }}$ represent the total decay time and decay time for radiative transition. The decay time for radiative transition ( $\tau_{\mathrm{rad}}$ ) of samarium (III) complexes was found to be $3.24 \mathrm{~ms}$ for transition ${ }^{6} \mathrm{G}_{5 / 2}$ manifold for $\mathrm{Sm}^{3+}$. The observed values reveal increase in quantum yield for $\mathrm{S} 2-\mathrm{S} 6$, relative to $\mathrm{S} 1$. This can be interpreted due to synergistic effect of ancillary ligand and lesser nonradiative transition which leads to increase in luminescence. It is noteworthy to emphasise that the luminescence decay time of the synthesised complexes is higher 
than most of the reported- [Sm(ligand) ${ }_{3}$.ancillary] complexes in literature, while life time was fetched by observing ${ }^{4} \mathrm{G}_{5 / 2} \rightarrow{ }^{6} \mathrm{H}_{7 / 2}$ emissive transition, as mentioned in Table 5 .

Table 5

Comparison of decay time of our synthesized complexes with other [Sm(ligand) ${ }_{3}$.ancillary] complexes when decay time was calculated by monitoring ${ }^{4} \mathrm{G}_{5 / 2} \rightarrow{ }^{6} \mathrm{H}_{7 / 2}$ electronic transition

\begin{tabular}{|lll|}
\hline Complex & Decay time $(\mathrm{ms})$ & Reference \\
\hline $\mathrm{Sm}(\mathrm{L})_{3} \cdot{ }_{2} \mathrm{H}_{2} \mathrm{O}$ & 0.72 & This work \\
\hline$\left[\mathrm{Sm}(\mathrm{L})_{3} \cdot\right.$ bipy $]$ & 1.40 & This work \\
\hline$\left[\mathrm{Sm}(\mathrm{L})_{3} \cdot\right.$ neo $]$ & 1.78 & This work \\
\hline$\left[\mathrm{Sm}(\mathrm{L})_{3} \cdot \mathrm{dmph}\right]$ & 2.02 & This work \\
\hline$\left[\mathrm{Sm}(\mathrm{L})_{3} \cdot\right.$ batho] & 2.41 & This work \\
\hline$\left[\mathrm{Sm}(\mathrm{L})_{3} \cdot\right.$ phen] & 2.15 & This work \\
\hline$\left[\mathrm{Sm}(\mathrm{HDMPE})_{3} \cdot \mathrm{phen}\right]$ & 0.99 & {$[35]$} \\
\hline$\left[\mathrm{Sm}(\mathrm{HDMPE})_{3} \cdot\right.$ biq $]$ & 0.90 & {$[36]$} \\
\hline$\left[\mathrm{Sm}(\mathrm{L})_{3} \cdot \mathrm{mphen}\right]$ & 0.56 & {$[37]$} \\
\hline $\mathrm{Sm}(\mathrm{L})_{3} \cdot 2 \mathrm{H}_{2} \mathrm{O}$ & 0.44 & {$[38]$} \\
\hline
\end{tabular}

\subsection{Colorimetric analysis}

The emission spectra of luminescence investigation used to determine the color coordinates $(x, y)$ of all S1-S6 complexes by utilizing MATLAB software. CIE (Commission International de l'Elclairge) color coordinates of all S1-S6 complexes are found to be $0.5542,0.4447$ (S1), 0.5560, 0.4430 (S2), 0.5702, 0.4288 (S3), 0.5521, 0.4468 (S4), 0.5558 , 0.4432 (S5) and $0.5573,0.4417$ (S6) respectively, enlisted in Table 4. CIE color triangle (Figure 7), displays the observed color coordinates of all S1-S6 complexes, which authenticate the effective sensitization of $\mathrm{Sm}^{3+}$ ions by the $L$ in reddish-orange zone [39]. Amazingly, these bright reddish-orange colors of complexes can be explored in color indicator diodes.

Color purity (CP) of all complexes is ascertained by employing CIE color coordinates with respect to white light, which shows how actively a meticulous complex act as reddish orange color emitter. CP of all complexes was calculated by using the following relation:

$$
C P=\sqrt{\frac{\left(x_{s}-x_{i}\right)^{2}+\left(y_{s}-y_{i}\right)^{2}}{\left(x_{d}-x_{i}\right)^{2}+\left(y_{d}-y_{i}\right)^{2}}}(9)
$$

In aforementioned equation, $\left(x_{s}, y_{s}\right)$ represents color coordinates of S1-S6 complexes, $\left(x_{i}, y_{i}\right)$ refers to white light color coordinates $\left(x_{i}=0.33, y_{i}=0.33\right)$ and $\left(x_{d}, y_{d}\right)$ represents the dominated color coordinates. CP determined by equation 9 is reported in Table 4, which specify that the color purity of S2-S6 is significantly higher as compared to S1. This fact 
is explained on the basis of synergic effect of ancillary ligands in place of solvent molecules. Hence, these complexes are proved to be bright orange color emitting materials to be utilized in OLEDs.

Further, an important parameter CCT (correlated color temperature) helps to investigation the quality and nature of light emitted from a light source. Depending on their CCT values, the complexes are cool light source (above 4000K), warm light source (below 3200K) and neutral light source (3200-4000K)[34]. The CCT can be evaluated by applying the Mc-Camy equation:

CCT $=-437 n^{3}+3601 n^{2}-6861 n+5514.31(10)$

Where $\mathrm{n}$ can be written as:

$\mathrm{n}=\frac{x-x_{e}}{y-y_{e}}$

Here, $(x, y)$ displays the CIE color coordinates of all S1-S6 complexes and $\left(x_{e}, y_{e}\right)$ stands for chromaticity epicentre $(0.3320,0.1858)$. Observed values of CCT for all S1-S6 complexes are found to be below 3200K (Table 4) indicating the applicability of these complexes in home appliances as a warm light source.

\subsection{Energy transfer dynamics}

The photosensitization is a multistep phenomenon that manifest the excitation of $L$ from ground state to singlet excited state, thereafter energy is transferred to triplet state by intersystem crossing and then to emitting levels of samarium (III) ions via nonradiative process. Further, energy transfer from emitting levels to ground levels of samarium (III) ions is responsible for luminescence as portrayed in Figure 8. It is important to note that there must be suitable energy gap between ligands and metal ions for effective sensitization, the smaller or larger energy gap leads to weak luminescence due to either back energy transfers or inadequate overlaps among acceptor energy levels. The overlap between the absorption spectrum of ligand and excitation spectrum of complex (S1) displayed in Figure S3 put in supplementary file, which indicates the effective sensitization of samarium (III) ions by the L. In order to investigate the energy transfer mechanism the singlet and triplet state of ligand and ancillary ligands are calculated by referring the edge wavelength of absorption spectrum and shortest emission of phosphorescence spectrum of gadolinium complexes respectively. The absorbance spectrum of dmph and neo is shown in Figure S4 and S5 in supplementary file and their inset represent phosphorescence spectra of gadolinium complexes respectively. The absorbance spectrum of $L$ is displayed in Figure 9 and phosphorescence spectrum of gadolinium complex of ligand is shown in inset of this figures. The photoluminescence acquired by gadolinium complexes is $32,000 \mathrm{~cm}^{-1}$ (lowest possible excitation), which is much higher than the photoluminescence of ligands, hence the peak due to gadolinium complex is not observed in spectrum. The energy difference between singlet and triplet state of $L$ is found to be $3320 \mathrm{~cm}^{-1}$, hence intersystem crossing is not much effective (Empirical rule), which results in internal conversion of energy from ligand to metal ion [40]. Further, Latva's rule state that the energy difference between ligand and lanthanides ions must be $2000-5000 \mathrm{~cm}^{-1}$ for effective energy transfer[41]. Energy difference between singlet and triplet states of ligand and ancillary ligands are found to be $4719 \mathrm{~cm}^{-1}$ (L), $4433 \mathrm{~cm}^{-1}$ (phen), $5233 \mathrm{~cm}^{-1}$ (bipy), 3430 $\mathrm{cm}^{-1}$ (dmph), $4957 \mathrm{~cm}^{-1}$ (neo) and $3333 \mathrm{~cm}^{-1}$ (batho) as tabulated in Table 6 with respect to samarium ion, which as optimum to efficient transfer of energy. 
Table 6

The energies of $L$, phen, bipy, dmph, neo and batho ancillary ligands.

\begin{tabular}{|c|c|c|c|c|}
\hline \multirow[t]{2}{*}{ Ligands } & \multicolumn{2}{|l|}{ Energy levels } & \multirow[t]{2}{*}{$\Delta \mathrm{E}\left(\mathrm{S}_{1} \rightarrow \mathrm{T}_{1}\right)\left(\mathrm{cm}^{-1}\right)$} & \multirow[t]{2}{*}{$\Delta \mathrm{E}\left(\mathrm{T}_{1} \rightarrow^{4} \mathrm{G}_{5 / 2}\right)\left(\mathrm{cm}^{-1}\right)$} \\
\hline & Singlet $\left(\mathrm{cm}^{-1}\right)$ & Triplet $\left(\mathrm{cm}^{-1}\right)$ & & \\
\hline $\mathrm{L}$ & 25,706 & 22,386 & 3320 & 4719 \\
\hline Phen & 31,000 & 22,100 & 8900 & 4433 \\
\hline Bipy & 29,900 & 22,900 & 7000 & 5233 \\
\hline Dmph & 31,250 & 21,097 & 10154 & 3430 \\
\hline $\mathrm{Neo}$ & 30,750 & 22,624 & 8126 & 4957 \\
\hline Bathophen & 29,000 & 21,000 & 8000 & 3333 \\
\hline
\end{tabular}

\subsection{Evaluation of Biological properties}

\subsubsection{Antioxidant features}

Figure 10(a) represents the percentage scavenging activities of all title complexes with respect to the standard ascorbic acid at $517 \mathrm{~nm}$. The $\mathrm{IC}_{50}$ values are observed from the plot between scavenging activity (SCA) and different concentration of samples are portrayed in figure 10(b) and enlisted in Table 7. Larger value of SCA leads to lower value of $\mathrm{IC}_{50}$, results higher antioxidant capacity of synthesized complexes. The stable free radical of DPPH adopt diamagnetic character by accepting a proton from antioxidant moiety, hence show decrease in absorbance so scavenging activity increases[36]. The antioxidant activities of all S1-S6 complexes are good as compared to ligand, due to donation of electrons from $\mathrm{L} \rightarrow \mathrm{Sm}^{3+}$, which increase the capability of complexes to oxidise. Further, it is evident from the table that the antioxidant activities of S2 - S6 complexes are higher than S1, explained on the basis of synergic effect produced by ancillary ligands. These complexes have excellent antioxidant activities so can be used as antioxidant agent in pharmaceutical field.

Table 7

$\mathrm{IC}_{50}$ values for antioxidant activities of $\mathrm{L}$ and all S1-S6 samarium (III) complexes

\begin{tabular}{|llllll|}
\hline Compounds & \multicolumn{5}{c|}{ Concentration $(\mu \mathrm{g} / \mathrm{mL})$} \\
\cline { 2 - 6 } & 100 & 50 & 25 & 12.25 & IC $_{50}$ \\
\hline L & 86.20 & 69.25 & 55.59 & 36.35 & 44.42 \\
\hline S 1 & 88.00 & 69.40 & 57.00 & 40.32 & 40.61 \\
\hline S 2 & 88.62 & 70.67 & 56.46 & 41.21 & 39.79 \\
S 3 & 88.73 & 72.34 & 56.43 & 42.72 & 38.09 \\
\hline S 4 & 89.36 & 71.07 & 57.42 & 43.41 & 37.35 \\
\hline S 5 & 89.57 & 74.02 & 59.13 & 44.98 & 34.05 \\
\hline S 6 & 87.01 & 70.33 & 57.59 & 43.07 & 37.49 \\
\hline STD & 88.79 & 76.22 & 64.49 & 52.89 & 19.39 \\
\hline
\end{tabular}




\subsubsection{Antimicrobial activities}

Figure 10(c) symbolize the antibacterial activities of all S1-S6 complexes in their corresponding minimum inhibitory concentration (MIC) values against both in vitro gram positive or in vitro gram negative bacteria. Further, Table 8 embodied the results observed form antimicrobial (antibacterial and antifungal) activities of all test samples with respect to standard by using tube dilution technique[35]. The antimicrobial activities of all synthesized complexes are higher than that of ligand due to delocalization of $\pi$ electrons, which results to increase in lipid attraction tendency of $\mathrm{L}$ towards $\mathrm{Sm}^{3+}$ ion. So, $\mathrm{Sm}^{3+}$ ion can access to deeper extent of microorganism cell and improve the antimicrobial activities by slow down the growth of microorganism [42]. On the basis of this fact, one can easily see that these complexes employed as good bactericidal and fungicidal agent in pharmaceutical field.

Table 8

Antimicrobial activities of L and all S1-S6 samarium (III) complexes.

\begin{tabular}{|c|c|c|c|c|c|c|c|}
\hline \multirow[t]{2}{*}{ Compounds } & \multicolumn{4}{|c|}{ Anti bacterial activities in term of their MIC values } & \multicolumn{3}{|c|}{$\begin{array}{l}\text { Antifungal activities in term of their MIC } \\
\text { values }\end{array}$} \\
\hline & $\begin{array}{l}E \text { Coli } \\
\text { Coll }\end{array}$ & $\begin{array}{l}P \\
\text { Aeruginosa }\end{array}$ & $\begin{array}{l}S . \\
\text { Aureus }\end{array}$ & $\begin{array}{l}\text { S. } \\
\text { Pyogenus }\end{array}$ & C. Albicans & A. Niger & A. Clavatus \\
\hline L & 145 & 270 & 180 & 260 & 200 & 800 & 800 \\
\hline S 1 & 115 & 220 & 120 & 180 & 150 & 210 & 220 \\
\hline S 2 & 105 & 190 & 115 & 150 & 150 & 220 & 180 \\
\hline S 3 & 90 & 130 & 125 & 100 & 150 & 180 & 190 \\
\hline S 4 & 80 & 120 & 62.5 & 90 & 140 & 220 & 120 \\
\hline S 5 & 50 & 90 & 40 & 70 & 120 & 130 & 180 \\
\hline S 6 & 65 & 110 & 50 & 80 & 130 & 140 & 90 \\
\hline STD & 10 & 10 & 10 & 10 & 500 & 1000 & 1000 \\
\hline
\end{tabular}

\section{Conclusions}

Six ternary complexes of samarium (III) ions by utilizing ketocarboxylic acid and ancillary ligands were synthesized and characterized. The proposed composition of complexes is confirmed by elemental analysis and TGA/DTG investigation of complexes. Investigation of IR, UV-visible and NMR $\left({ }^{1} \mathrm{H} \&{ }^{13} \mathrm{C}\right)$ spectra of ligand and complexes in details confirm the formation of complexes. Besides, photoluminescence spectral studies shows that under $356 \mathrm{~nm}$ excitation, all synthesized complex exhibits the characteristics peaks at $566 \mathrm{~nm}, 606 \mathrm{~nm}$ and $651 \mathrm{~nm}$ which can be credited to $\left({ }^{4} \mathrm{G}_{5 / 2} \rightarrow{ }^{6} \mathrm{H}_{5 / 2}\right),\left({ }^{4} \mathrm{G}_{5 / 2} \rightarrow{ }^{6} \mathrm{H}_{7 / 2}\right)$ and $\left({ }^{4} \mathrm{G}_{5 / 2} \rightarrow{ }^{6} \mathrm{H}_{9 / 2}\right)$ electronic transitions of $\mathrm{Sm}^{3+}$ respectively. The energy band gap and refractive index of all complexes and ligand are determined precisely, which enables the applicability of them in semiconductor devices. Investigation of luminescence decay time in detail provide the homogenous environment around samarium (III) ion with excellent intrinsic lifetime (0.7 2-2.42) of all synthesized complexes. CIE colors coordinates, quantum yield (22.22-74.38) and color purity (98.01-99.04) of all S1-S6 complexes were determined accurately. According to CCT, these complexes are warm in appearance. Energy transfer dynamics validates the successfull transfer of energy from ligand (triplet energy state) to samarium (III) ion (resonating energy states). Biological activities of these complexes display the potential use of these complexes in pharmaceutical field. 
All results validate that these samarium (III) complexes can be utilized in lasers, display devices, OLED's, semiconductors and biological assays.

\section{Declarations}

\section{Authors Declarations}

\section{Acknowledgement}

One of authors, Pooja Hooda gratefully acknowledges the Department of Chemistry, Maharshi Dayanand University Rohtak for providing instrumental facilities.

\section{Funding}

Pooja Hooda, One of these authors appreciates the financial support from Council of Scientific and Industrial Research (CSIR) in New Delhi, India in form of senior research fellowship (SRF) (Award No: 09/ 382(0207)/2019-EMR1) to complete this research work.

\section{Data Availability}

All data analysed during this study are included in this article and its supplementary information.

\section{Code Availability}

No software or any computational study was not used for this study.

\section{Authors' contributions}

Pooja Hooda performed experimental works, data collection, analysis, validation, interpretation and wrote the original manuscript. Savita Khatri and Poonam Kumari contributed to the experimental, reviewed and edited manuscript. V. B. Taxak, R. K. Malik, S. P. Khatkar, and Rajesh Kumar contribute to supervision, technical support, editing functions and manuscript review.

\section{Ethics Declarations}

\section{Ethics Approval/Declarations}

Not Applicable

\section{Consent to Participate}

Not Applicable

\section{Consent for Publication}

Not Applicable

\section{Conflicts of Interest/Competing Interests}

The authors say no conflicts of interest regarding this research work. 


\section{References}

1. Khatkar SP, Kumar R, Khatkar A, Taxak VB (2015) Synthesis, characterization, enhanced photoluminescence and biological activity of Eu (III) complexes with organic ligands.J Mater Sci Mater Electron26:7086-7095

2. Khanagwal J, Khatkar SP, Dhankhar P et al (2020) Synthesis and photoluminescence analysis of europium (III) complexes with pyrazole acid and nitrogen containing auxiliary ligands.Spectrosc Lett53:625-647

3. Liu Y, Tu D, Zhu H, Chen X (2013) Lanthanide-doped luminescent nanoprobes: controlled synthesis, optical spectroscopy, and bioapplications. Chem Soc Rev42:6924-6958

4. Wang D, Zheng C, Fan L et al (2014) Photoluminescence behavior of europium (III) complexes containing 1-(4tert-butylphenyl)-3-(2-naphthyl)-propane-1, 3-dione ligand.Spectrochim Acta Part A Mol Biomol Spectrosc117:245-249

5. Refat MS, El-Hawary WF, Moussa MAA (2011) IR, 1H NMR, mass, XRD and TGA/DTA investigations on the ciprofloxacin/iodine charge-transfer complex.Spectrochim Acta Part A Mol Biomol Spectrosc78:1356-1363

6. Taxak VB, Khatkar SP (2012) Synthesis and Luminescent Properties of M 2 V 2 O 7: Eu (M= Sr, Ba) Nanophosphors.J Fluoresc22:891-897

7. Leonzio M, Melchior A, Faura G et al (2018) A chiral lactate reporter based on total and circularly polarized Tb (III) luminescence.New J Chem42:7931-7939

8. Devi R, Chahar S, Khatkar SP et al (2017) Relative study of luminescent properties with Judd-Ofelt characterization in trivalent europium complexes comprising ethyl-(4-fluorobenzoyl) acetate.J Fluoresc27:13491358

9. Chahar S, Taxak VB, Dalal M et al (2016) Structural and photoluminescence investigations of Sm3+ doped BaY2ZnO5 nanophosphors. Mater Res Bull77:91-100

10. Zhang Z, Tang R (2012) Synthesis and fluorescence properties of Tb (III) complex with a novel $\beta$-diketone ligand as well as spectroscopic studies on the interaction between Tb (III) complex and bovine serum albumin.J Mol Struct1010:116-122

11. Kumar R, Boora P, Khatkar A et al (2016) Synthesis, photoluminescence and biological properties of terbium (III) complexes with hydroxyketone and nitrogen containing heterocyclic ligands.Spectrochim Acta Part A Mol Biomol Spectrosc152:304-310

12. Sarıoğlu AO, Yalçın ŞP, Ceylan Ü et al (2020) Photoluminescence properties of samarium (III)-based complexes: Synthesis, characterization and single crystal X-ray.J Lumin227:117537

13. Kumar R, Makrandi JK, Singh I, Khatkar SP (2008) Preparation and photoluminescent properties of europium complexes with methoxy derivatives of 2'-hydroxy-2-phenylacetophenones.J Lumin128:1297-1302

14. Kassim NK, Lim PC, Ismail A, Awang K (2019) Isolation of antioxidative compounds from Micromelum minutum guided by preparative thin layer chromatography-2, 2-diphenyl-1-picrylhydrazyl (PTLC-DPPH) bioautography method.Food Chem272:185-191

15. Rieckmann KH, Sax LJ, Campbell GH, Mrema JE (1978) Drug sensitivity of P. falciparum. An in vitro microtechnique.Lancet1:22-23

16. Hooda P, Taxak VB, Malik RK et al (2021) Designing of emerald terbium (III) ions with $\beta$-ketocarboxylic acid and heterocyclic ancillary ligands for biological and optoelectronic applications. Luminescence

17. Perkampus H (1976) LJ Bellamy: The Infrared Spectra of Complex Molecules, Vol. 1, 3. Auflage, Chapman and Hall Ltd., London 1975, 433 Seiten, 32 Abb., 22 Tabellen, Preis:£ $8 . \& \# 8212$ 
18. Khanagwal J, Kumar R, Hooda P et al (2021) Designing of luminescent complexes of europium (III) ion with hydroxyl ketone and nitrogen donor secondary ligands for improving the luminescence performance and biological actions.Inorganica Chim Acta525:120463

19. Refat MS (2007) Synthesis and characterization of norfloxacin-transition metal complexes (group 11, IB): spectroscopic, thermal, kinetic measurements and biological activity.Spectrochim Acta Part A Mol Biomol Spectrosc68:1393-1405

20. Bala M, Kumar S, Chahar S et al (2020) Synthesis, NMR and optical features of intense green color terbium (III) complexes.Optik (Stuttg)202:163636

21. Al-Omar MA (2005) Ciprofloxacin: analytical profile. Profiles of Drug Substances, Excipients and Related Methodology. Elsevier

22. Skauge T, Turel I, Sletten E (2002) Interaction between ciprofloxacin and DNA mediated by Mg2+-ions. Inorganica Chim Acta339:239-247

23. Bala M, Kumar S, Devi R et al (2018) Synthesis and photoluminescence properties of europium (III) complexes sensitized with $\beta$-diketonato and N, N-donors ancillary ligands.Spectrochim Acta Part A Mol Biomol Spectrosc196:67-75

24. Khanagwal J, Kumar R, Devi R et al (2021) Photoluminescence performance of green light emitting terbium (III) complexes with $\beta$-hydroxy ketone and nitrogen donor ancillary ligands.Luminescence36:742-754

25. Sadeek SA, El-Shwiniy WH, Zordok WA, El-Didamony AM (2011) Spectroscopic, structure and antimicrobial activity of new Y (III) and Zr (IV) ciprofloxacin.Spectrochim Acta Part A Mol Biomol Spectrosc78:854-867

26. Phogat $P$, Khatkar SP, Malik RK et al (2021) Crystal chemistry and photoluminescent investigation of novel white light emanating Dy3+ doped Ca9Bi (VO4) 7 nanophosphor for ultraviolet based white LEDs.Mater Chem Phys124828

27. Sehrawat $P$, Khatkar A, Boora P et al (2020) Tailoring the tunable luminescence from novel Sm3+ doped SLAO nanomaterials for NUV-excited WLEDs.Chem Phys Lett755:137758

28. Khanagwal J, Kumar R, Bedi M et al (2021) Enhanced Optoelectronic and Biological Potential of VirescentGlowing Terbium (III) Complexes with Pyrazole Acid.J Electron Mater50:2656-2668

29. Bedyal AK, Kumar V, Ntwaeaborwa OM, Swart HC (2014) A promising orange-red emitting nanocrystalline NaCaB03: Sm3+ phosphor for solid state lightning.Mater Res Express1:15006

30. Devi S, Khatkar A, Taxak VB et al (2018) Optical properties of trivalent samarium-doped Ba5Zn4Y8021 nanodiametric rods excitable by NUV light.J Alloys Compd767:409-418

31. Hooda A, Khatkar SP, Khatkar A et al (2019) Crystal structure, synthesis and photoluminescent properties of a reddish-orange light emitting SrGdAlO4: Sm3+ nanophosphor.Mater Chem Phys232:39-48

32. Yan B, Song YS (2004) Spectroscopic study on the photophysical properties of lanthanide complexes with 2, 2'bipyridine-N, N'-dioxide.J Fluoresc14:289-294

33. Parker D (2000) Luminescent lanthanide sensors for pH, pO2 and selected anions.Coord Chem Rev205:109-130

34. Chauhan A, Langyan R (2020) Preparation and optical features of samarium (III) complexes introducing bidentate fluorinate and secondary ligands.J Mater Sci Mater Electron31:22085-22097

35. Nandal P, Kumar R, Khatkar A et al (2016) Synthesis, characterization, enhanced photoluminescence, antimicrobial and antioxidant activities of novel Sm (III) complexes containing 1-(2-hydroxy-4, 6dimethoxyphenyl) ethanone and nitrogen containing ancillary ligands.J Mater Sci Mater Electron27:878-885

36. Nandal P, Kumar R, Sheetal SP, Taxak VB (2018) Preparation, Photoluminescent Behaviour, Antimicrobial and Antioxidant Properties of New Orange Light Emitting Sm (III) Complex, Sm (CHME) 3. Dmphen 
37. Chauhan A, Malik RK, Lohra S, Langyan R (2021) Investigation of photophysical properties of ternary Sm (III) complexes.Optik (Stuttg)242:167078

38. Chauhan A, Langyan R (2021) Preparation, characterization and luminescence behavior of some samarium complexes.Rare Met40:2618-2626

39. Dar WA, Ganaie AB, Iftikhar K (2018) Synthesis and photoluminescence study of two new complexes [Sm (hfaa) 3 (impy) 2] and [Eu (hfaa) 3 (impy) 2] and their PMMA based hybrid films.J Lumin202:438-449

40. Räsänen M, Takalo H, Rosenberg J et al (2014) Study on photophysical properties of Eu (III) complexes with aromatic $\beta$-diketones-Role of charge transfer states in the energy migration.J Lumin146:211-217

41. Latva M, Takalo H, Mukkala V-M et al (1997) Correlation between the lowest triplet state energy level of the ligand and lanthanide (III) luminescence quantum yield.J Lumin75:149-169

42. Liu J-Y, Ren N, Zhang J-J, Zhang C-Y (2013) Preparation, thermodynamic property and antimicrobial activity of some rare-earth (III) complexes with 3-bromo-5-iodobenzoic acid and 1, 10-phenanthroline.Thermochim Acta570:51-58

\section{Figures}

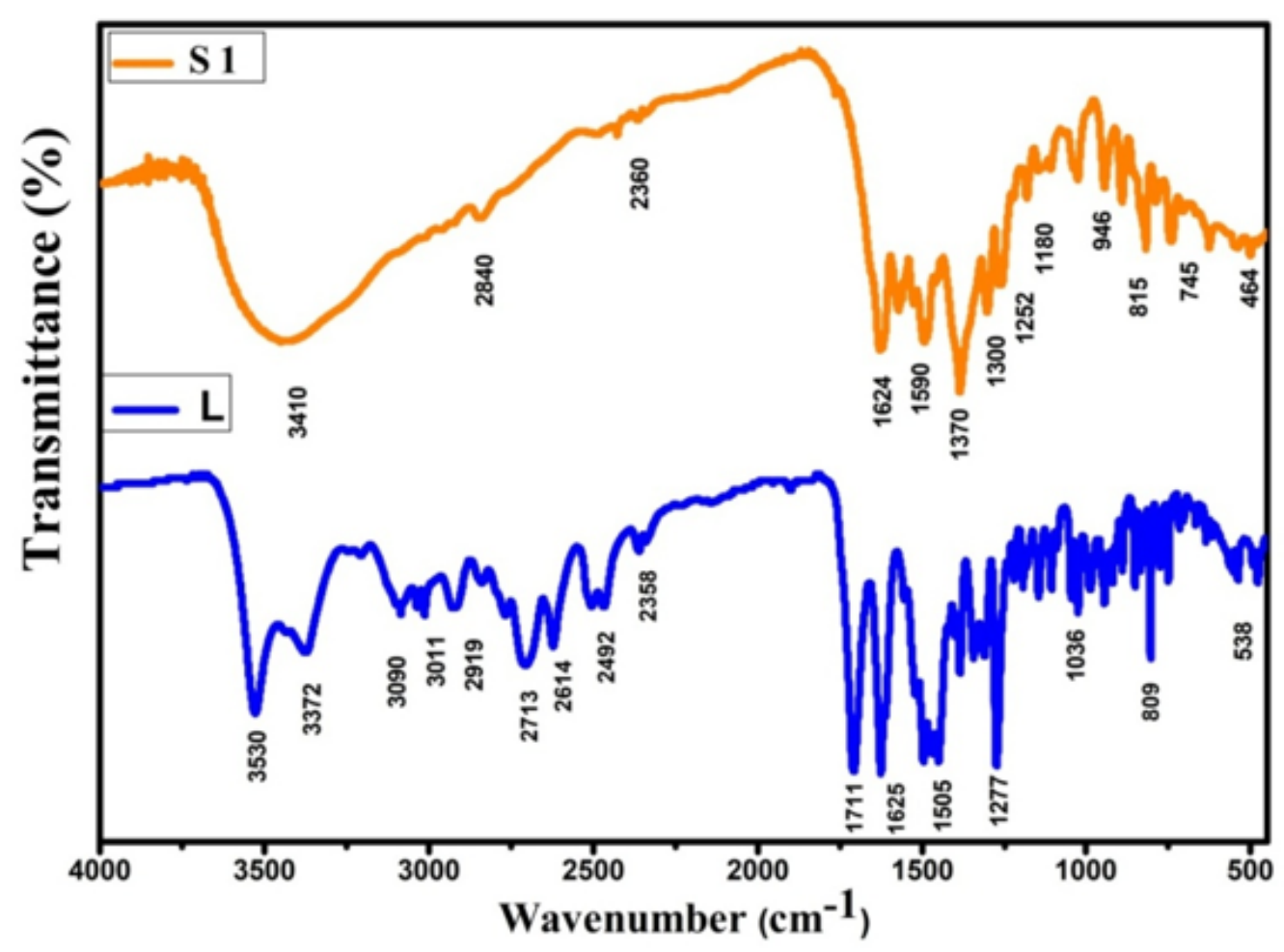

Figure 1

The IR spectra of $L$ and S1 complex. 


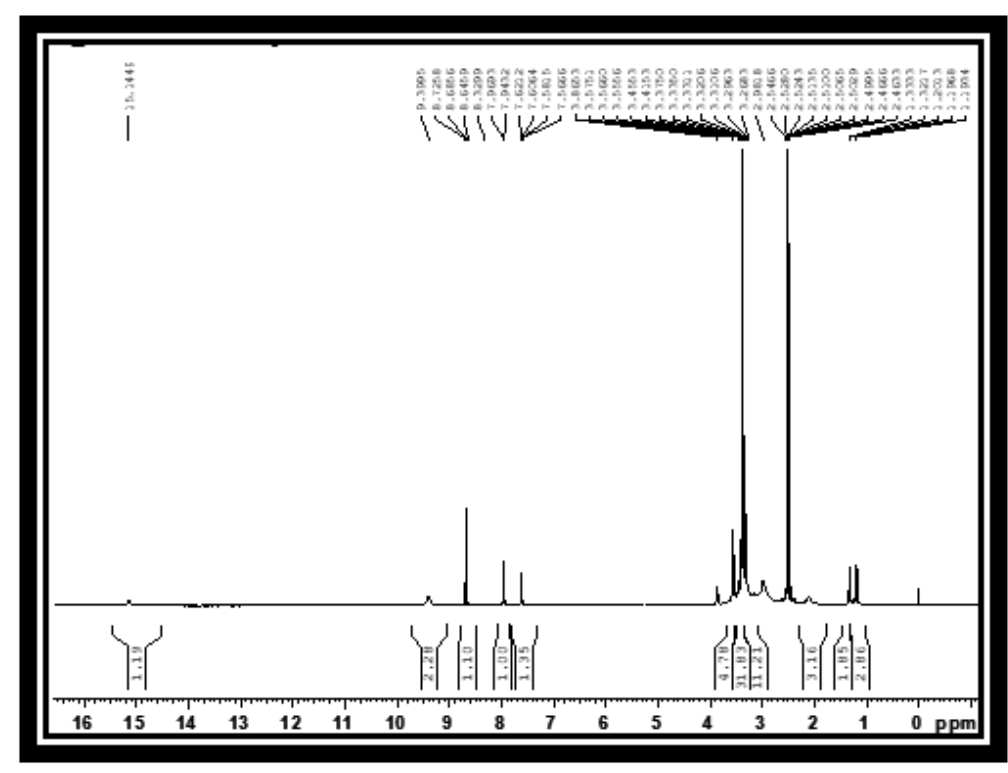

(L)

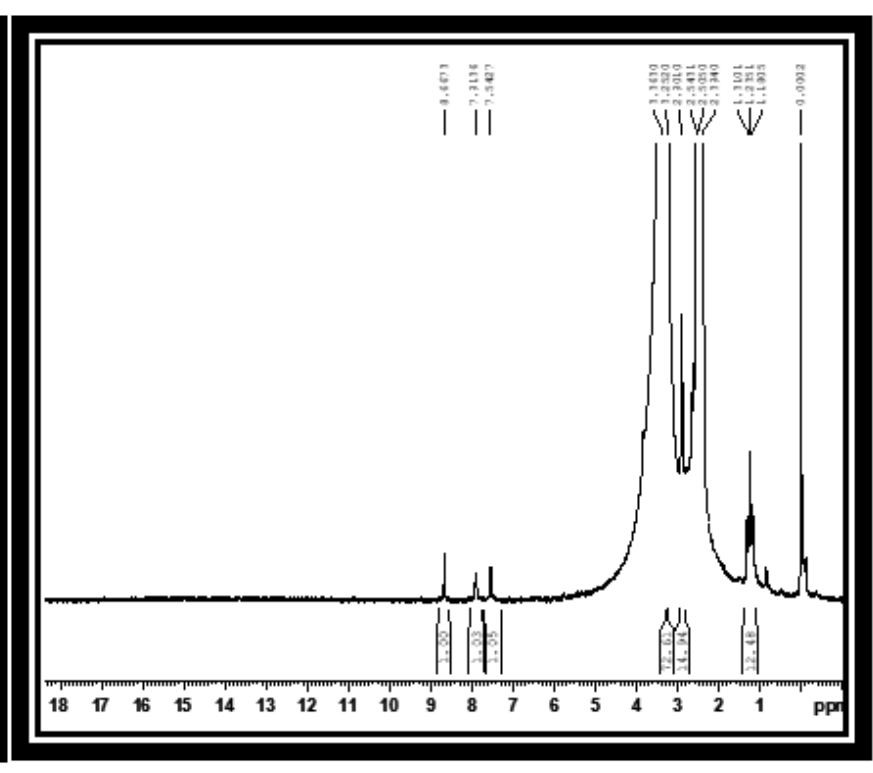

(S 1)

Figure 2

The $1 \mathrm{H}-\mathrm{NMR}$ spectrum of ligand $\mathrm{L}$ and its S1 complex.

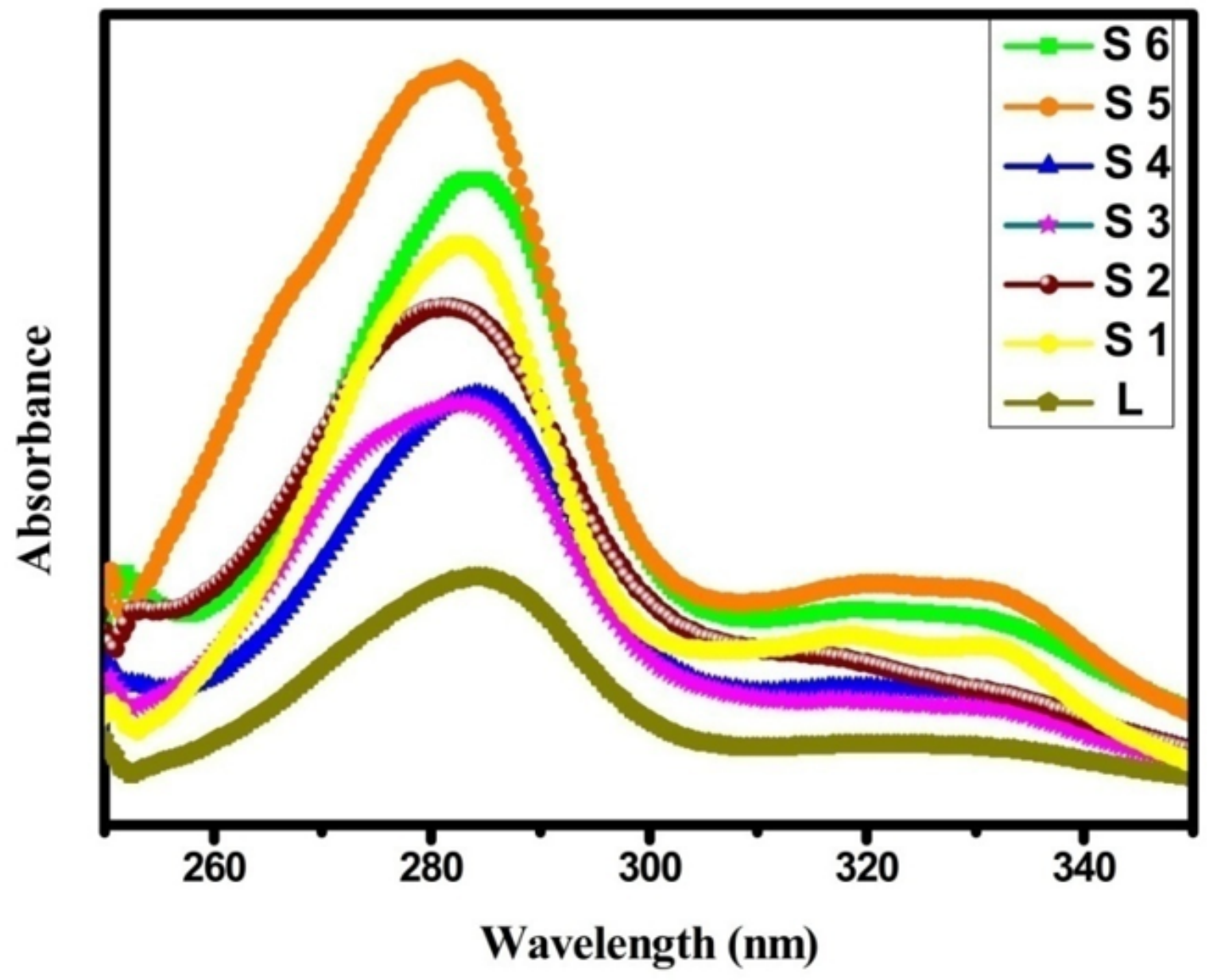

Figure 3 


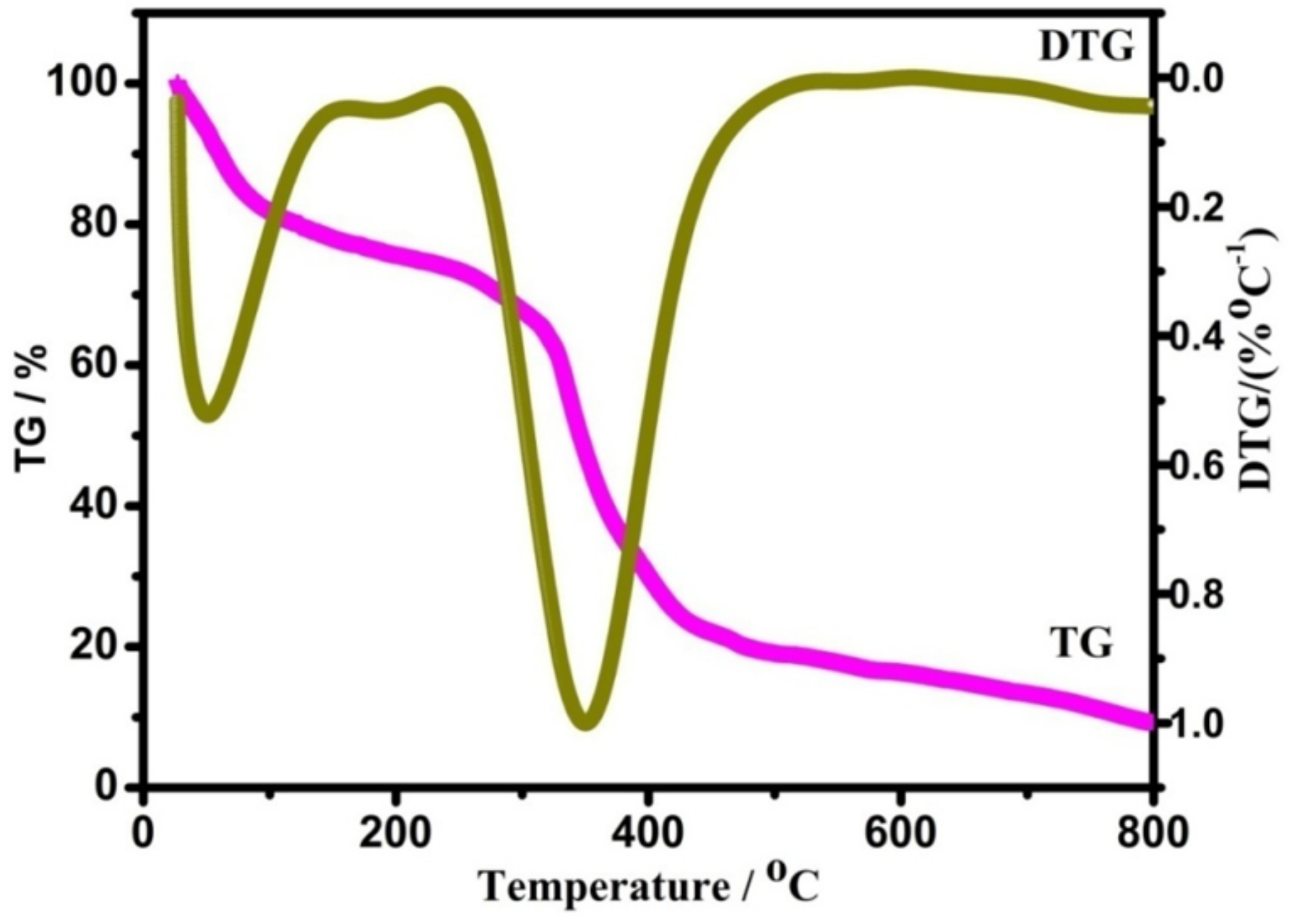

Figure 4

TG/DTG curve of S1 complex of samarium in nitrogen atmosphere.
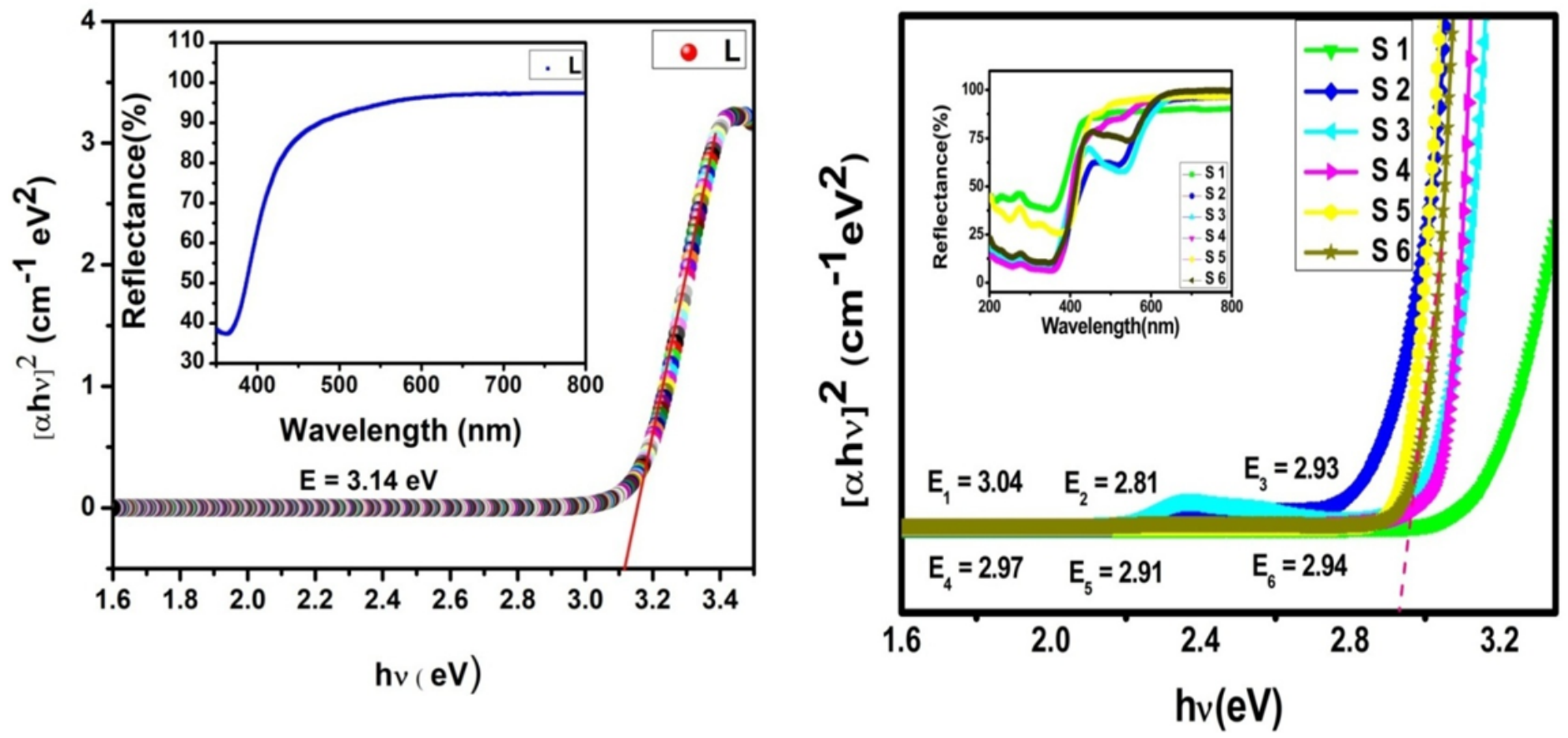
Figure 5

(a) The diffused reflectance spectrum of ligand and inset represent the corresponding reflectance spectrum. (b) The diffused reflectance spectra of S1-S6 complexes and inset displays its corresponding reflectance spectra.
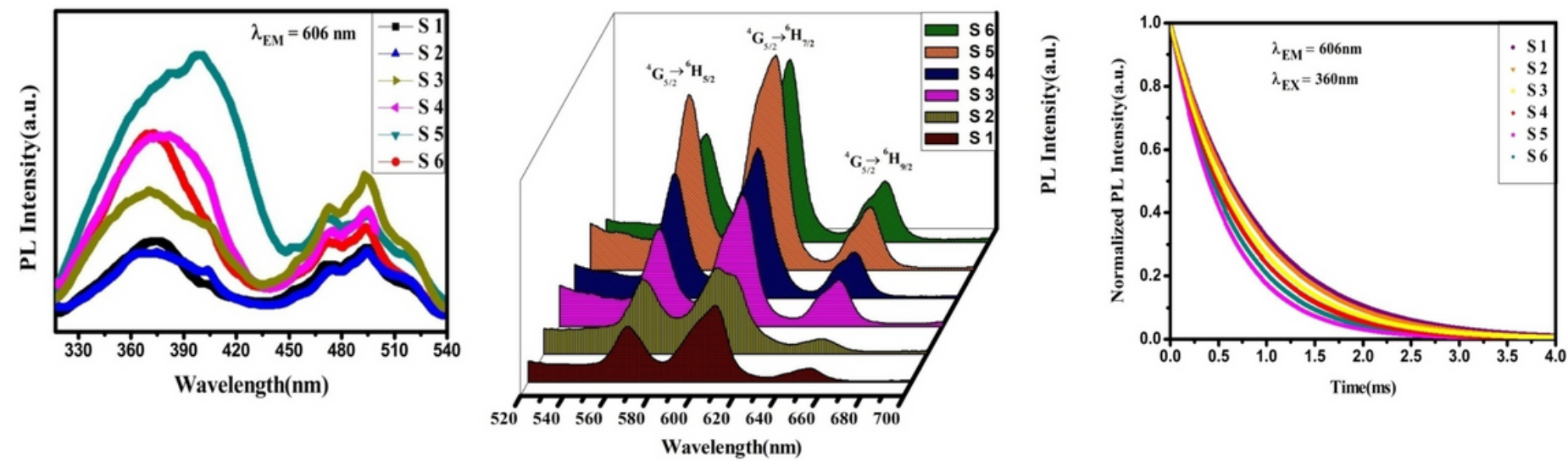

Figure 6

(a) The excitation spectra of all S1-S6 complexes monitored at $606 \mathrm{~nm}$. (b) the emission spectra of all S1-S6 complexes monitored at $356 \mathrm{~nm}$. (c) Luminescence decay curves for all S1-S6 complexes monitored at $\otimes \mathrm{EM}=606 \mathrm{~nm}$ and $\triangle E X=356 \mathrm{~nm}$.

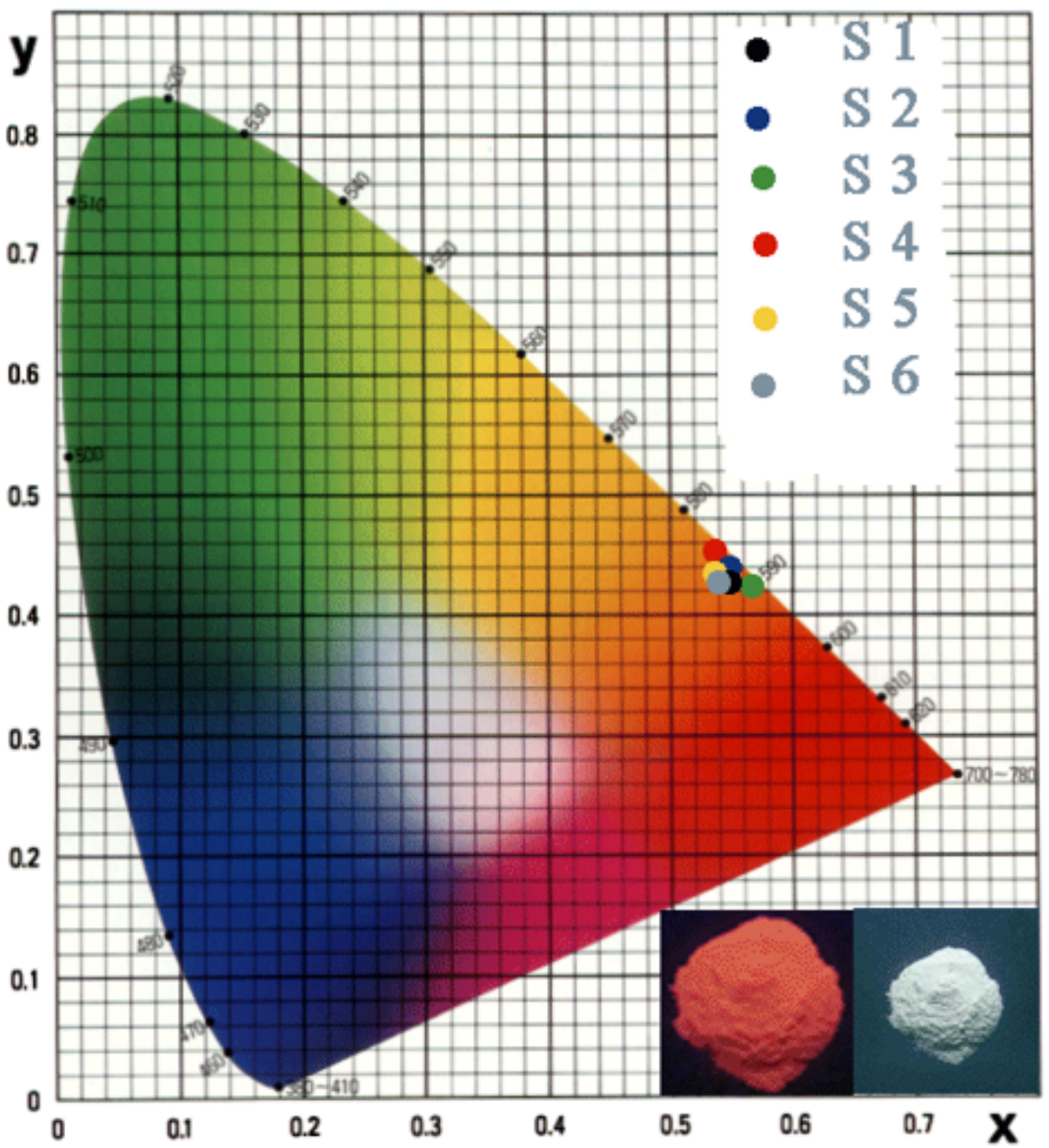

Figure 7 
CIE color coordinates representation of all S1-S6 complexes.

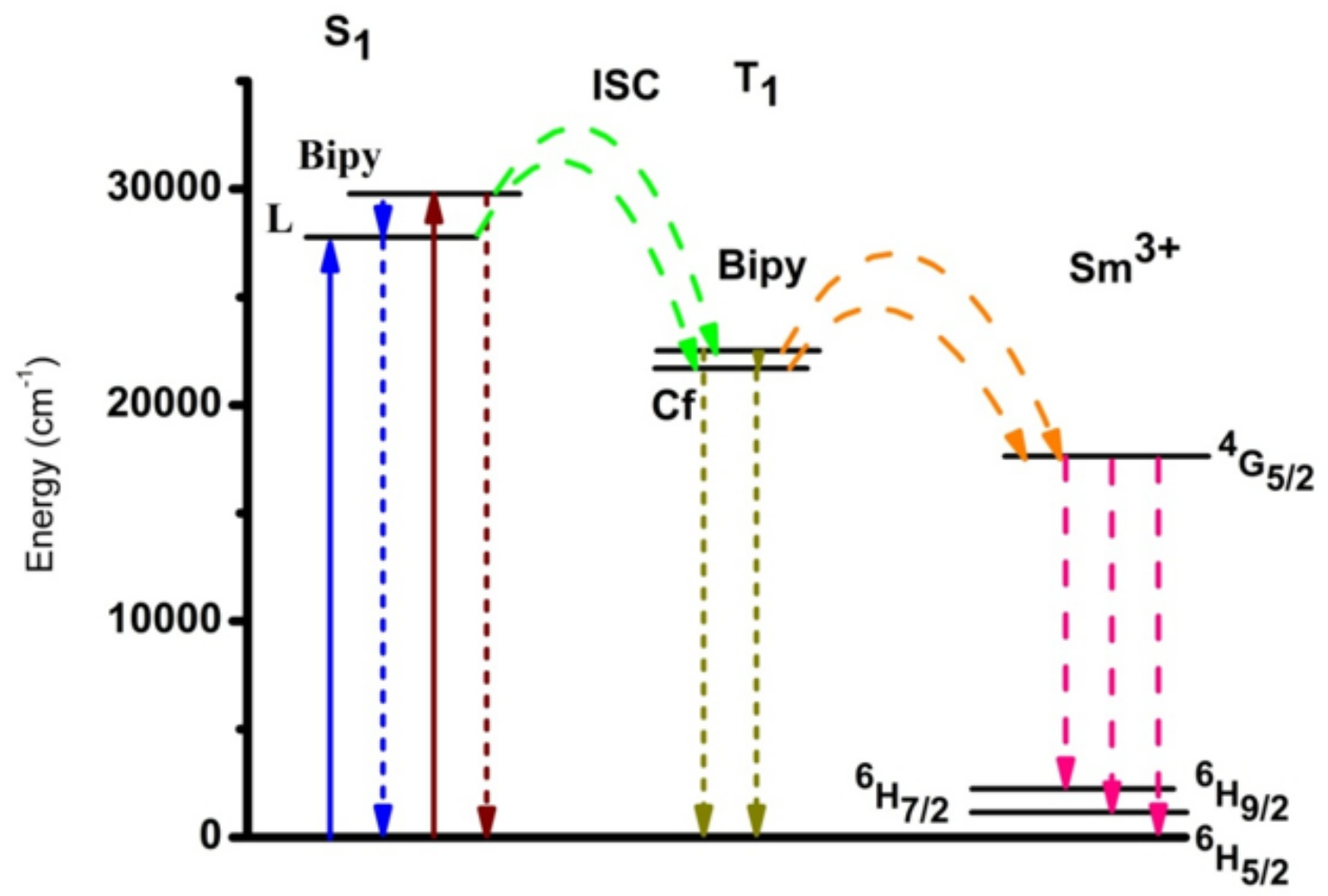

Figure 8

The systematic energy transfer pathway for [Sm(L)3.bipy].6H2O complex.

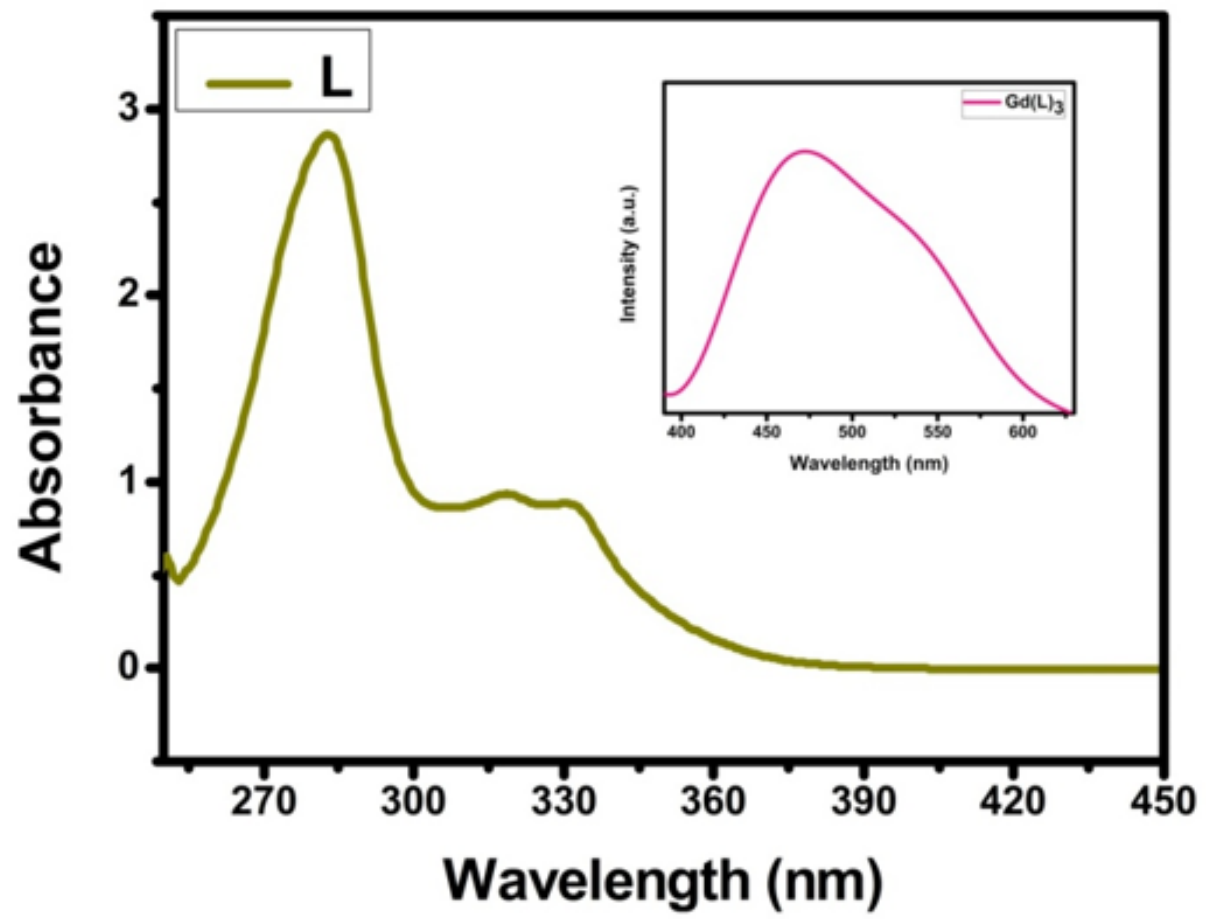

Figure 9 
The absorbance of ligand spectrum and inset represent the phosphorescence spectrum of corresponding gadolinium complex.
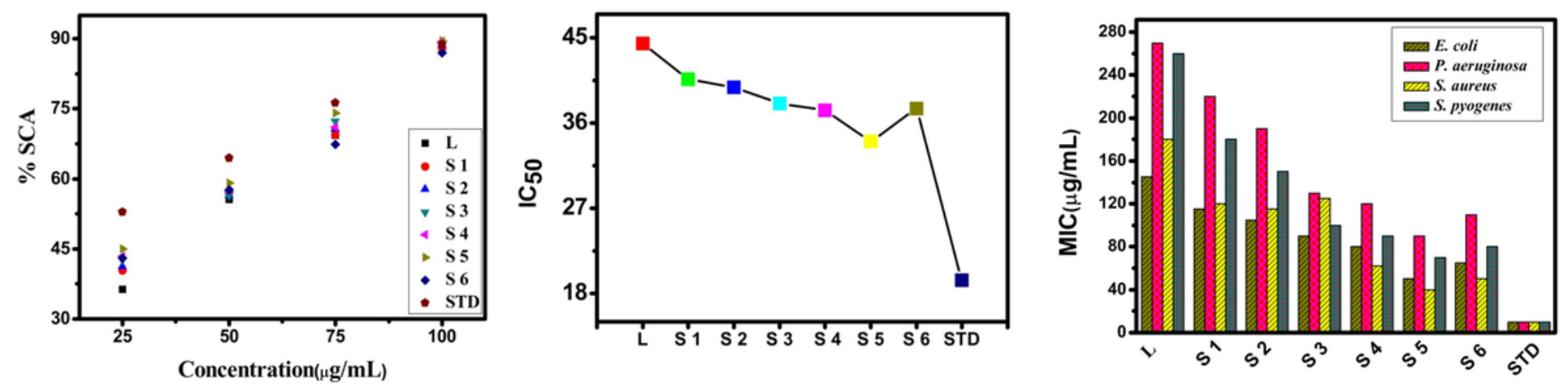

Figure 10

(a) Percentage scavenging activity of L and S1-S6 complexes with respect to standard drugs. (b) The IC50 values of ligand and all synthesized complexes with respect to standard drugs. (c) The antibacterial activities of L and all S1-S6 complexes with respect to standard drugs.

\section{Supplementary Files}

This is a list of supplementary files associated with this preprint. Click to download.

- SupplimentryMaterial.docx 